\title{
NON STANDARD USES OF IF
}

\author{
D.S. Bree \& R.A. Smit \\ Rotterdam School of Management \\ Erasmus University \\ P.O. Box 1738 \\ 3000 DR Rotterdam \\ The Netherlands
}

\begin{abstract}
The present study examines the semantic problems involved in computing the meaning of the non standard uses of if. The central question is whether or not it is necessary to introduce different meanings of if.

Austin proposed two non standard meanings for if. We show that these can be accounted for by the standard meanirg together with shifts in the position of the speech act within the sentence. These uses of if are among the 9 different non standard uses which we found in a sample of if sentences taken from the Brown University corpus:
\end{abstract}

1. Counterfactual:

If $E$ had stuck to his plan he'd still be famous.

2. Factual:

If $R$ was a liar, he was also a canny gentleman.

3. Conditional speech act:

You may come back to Strasbourg, now, if you wish.

4. Performative speech act:

He vowed vengence on $L$, if ever the chance came his way.

5. Noun clause:

He wondered if the audience would let him finish.

6. Doubtful presupposition

Perfect entities, if they move at all, don't move to ...

7. Restrictive

Social relations impose courtesy, if not sympathy,

Concessive

9. Protasis only

"If you want to see -" "Never mind", she said sternly.

Each use was examined to see whether it could be accounted for by the standard meaning of if, together with other features of the sentence. Similar differences in usage should then be found with other SCs. This was the case for the first four uses. In three uses $(6,7,8)$ if may/must occur in a phrase rather than in a full clause. The hypothesis that these uses can be derived from the standard meaning of if in an equivalent clause was explored and rejected. Two of these uses $(6,7)$ require a material implication interpretation of if, also necessary for a few of the standard conditional sentences.

Two uses $(5,9)$ require only that the truth value of the following clause/phrase is unspecified. This is a property that all the uses have in common (with the exception of the factual use where the truth of the protasis is used to emphasise the truth of the apodosis) and is thus the feature that relates the different meanings of if. The standard use and the non standard uses using the standard meaning $(1,2,3,4)$ require, in addition, that there is an inference relation from the protasis (the if sub clause) to the apodosis (the main clause in which the if clause is embedded).

So we propose that three different meanings of if are required: inference (including the standard use), material implication (uses 6,7 ) and just doubting the truth value of the following proposition (uses 5,9). Each of these three uses may be expected to be translated by different words in other languages, e.g. in Dutch by als, zo and of (except for use 8 ) respectively.

\section{INTRODUCTION}

There has long been, and still is, a controversy about the meaning of if le.g. Grice, 1967; Stalnaker, 1975; Harper et al, 1981). Much of this discussion presupposes that there is indeed one meaning of if. Is this presupposition justified?

At one level the answer is clearly 'no', e.g. if can be used to introduce a noun clause following an illocutionary verb:

John asked if he could come in now. Such examples do not conform to the conditional use of if as in:

If John asked he could come in now.

This is so different a use of if that one might claim it should be set aside from the conditional if. Thus there would be two ifs: if " for subordinate clauses and if "for noun clauses.

Our question should be reformulated as: is there only one meaning of if'? Austin (1961) claimed that the ansiver was 'no', providing examples that did not conform to two logical properties that are associated with if'. There is a stipulative use of if' which does not contrapose, e.g. from 1. I promise to marry him if he asks me. one does not conclude that

If I do not promise to marry him, he does not ask me.

There is also an if of doubt or hesitation which not only fails to contrapose, but which also asserts the proposition underlying the main clause (the 'apodosis proposition'), e.g. from

2. There are biscuits on the table if you want some.

fails to contrapose, but also we are willing to accept the apodosis simpliciter. Can this claim be rebutted? 
We believe that it can be. Austin's fault lies in working with the surface structure rather than with the underlying propositions. He thus fails to take account of the scope of if and of the scope of the speech act involved. With conditional if', the condition falls within the scope of the speech act. When there is a performative verb in the apodosis, then the conditional is within the scope of the performative; so the performative itself is not within the conditional, just as with Austin's example of stipulative if'. Thus 1 is paraphrasable as:

I promise that I will marry him if he asks me. in which the promise is contraposable:

I promise that he does not ask me if I will not marry him.

In the case of an if of doubt or hesitation it is the speech act that falls within the scope of the conditional. Thus 2 is:

If you want biscuits, accept the declaration that there are some on the table.

This act of speech is to be noticed only when the proposition underlying the protasis (the if clause) holds; it is NOT made simpliciter.

This explanation of the reading of Austin's two ifs, based on the relative scopes of the speech act and if, can be extended to other subordinating conjunctions (SC's), e.g.

I promise to marry him unless/provided/when he's rich.

The case for the non-restrictive use, with the speech act falling within the scope of the SC was made by Rutherford (1970), e.g.

He'll marry you, unless I'm mistaken.

In view of this generality it is parsimonious to regard Austin's two ifs as two different uses arising out of the context of the speech act, rather than as two different meanings of if.

Rejecting Austin's ifs as possible contenders for an if' having a non standard meaning does not, however, show that there are no non standard meanings.

In fact the O.E.D suggests 9 different uses of if:

1. conditional;

2. semi-factual;

3. counterfactual;

4. a pregnant sense, e.g.

If they are poor, they are at any rate happy;

5. an archaic use with that;

6. an elliptic use, e.g. if at all;

7. the protasis alone, e.g. If I had only known;

8. in phrases, e.g. as if;

9. introducing a noun clause, e.g. ask if.

(Note that this list does NOT include Austin's two uses of if!)

To check whether or not there were further possible uses we have taken a $10 \%$ sample of if sentences from the Brown University corpus of American printed texts, available on magnetic tape (Kucera \& Francis, 1967). In our judgement in $61 \%$ of the 218 sentences in the sample, if was used in a standard conditional way. In $8 \%$ the if was preceded by some modifier, e.g. as if. This left 69 $(31 \%)$ non standard uses of if as possible contenders for different meanings of if.

\section{A TAXONOMY OF NON STANDARD IF}

To consider the possibility that some meanings of if differ from the conditional, we need some way of classifying the 69 non standard sentences in our sample. The taxonomy we chose is based on two features that are present in the conditional uses of if: if enables a proposition to be referred to or entertained without being asserted as being (possibly) true or false, and if signals an inference relation from the protasis proposition to the apodosis proposition. By an inference relation we mean that the apodosis proposition may be inferred from the protasis proposition, together with the context propositions. (See the critique of Bree (1973) on Wason and Johnson-Laird's (1972) proposal for the different interpretations of if.)

In the non standard uses of if one or the other of these two features is either absent or altered. Thus we propose that there are two major categories of non standard if:

A. in which the inference relation is present but the protasis proposition is NOT in doubt, being either true or false;

B. in which the truth status of the protasis proposition is in doubt, but the inference relation does not run from the protasis to the apodosis proposition.

This last class is divided into two subclasses:

Bl. in which the inference relation is present but with a different scope from the standard use;

B2. in which the inference relation is absent.

The complete classification of the sample of if sentences according to their different uses is shown in Table 1.

We will now consider each of the different uses in turn, in order to determine whether the use requires a different meaning of if from the standard conditional. We will check whether or not the non standard use is to be found with other SCs, so that it can be accounted for without postulating a new meaning; whether it is related to another non standard use, so that both uses are based on the same non standard meaning; or whether it requires its own idiosyncratic non standard meaning of if.

\section{Counterfactuals}

Counterfactual if, which is a problem for logicians, is straightforward from our point of view. An inference relation from the protasis proposition to that in the apodosis is being asserted, while it is known that the protasis proposition is false (Bree, 1982).

It is usual (16 of the 18 counterfactual sentences in our sample) for the apodosis proposition to be false (or a question), which is indicated by using the auxilary would:

(26) If Elaine's uncle had stuck to this desire for aloneness, he probably would still be alive.

(60) "Laura, what would you say if I smoked a pipe?" However the apodosis proposition may be true (1/18):

(76) (...) if it had never printed a word of literature its contribution to the politico-sociological area would still be historic.

The protasis alone is used to indicate that important (desirable) consequences would flow from the truth of the protasis:

(85) "If it wasn't for these dear children." 
Table 1. Surmary of the uses of if in the sample.

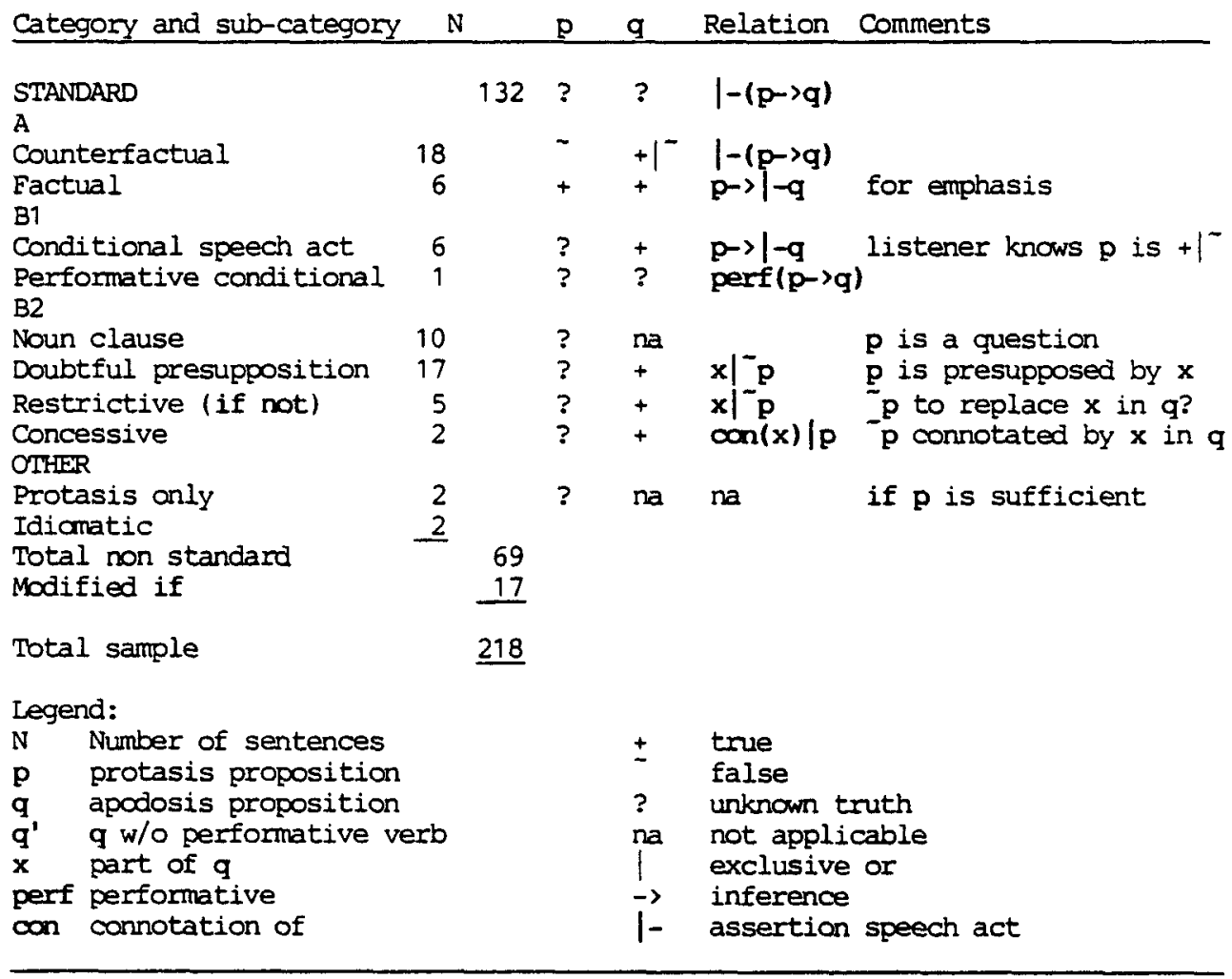

The counterfactual construction is not unique to if; it occurs with other SCs in which the truth status of the subordinate clause proposition is normally open, e.g.:

She wouldn't have married him unless she had loved him.

She would have married him provided he had asked her.

In both cases the main proposition is false; the subordinate proposition is true for unless and false for provided. Thus the counterfactual use should NOT be based on a different meaning of if, but rather in the use of the subjunctive mode.

\section{Factuais}

The protasis proposition may be true rather than false; this is the O.E.D. pregnant sense of if. In such cases the apodosis proposition is also true. Moreover there is no DIRECT relation from the protasis proposition to the apodosis proposition, so it is strange that if is being used at all. One possible explanation is that it is a slip for the more appropriate SC although, as in:

(113) If Robinson was a liar and a slanderer, he was also a very canny gentleman (...)

Sometimes it is used where cordination would be more suitable:
(174) If we thus spent our very first day in (...) our last day to us at least, was equally impressive (...)

But neither sense would be appropriate in

(185) If Wilhelm Reich is the Moses who has led them out of the Egypt of sexual slavery, Dylan Thomas is the poet who offers them the Dionysian dialectic of justification for their indulgence in liquor, (...)

A more satisfactory explanation is that it is the speech act that is conditional upon the protasis proposition. The writer is emphasising the speech act by prefacing it (the protasis must always occur before the apodosis in these factuals) with a proposition that he knows the reader will know to be true. The inference is from the protasis proposition to the speech act containing the apodosis, as in:

(178) (...) whether there is such fitness or not, we will assume that there is, and if we do, we express (...)

It is used with effect in emphasising an imperative:

(211) (...) so if you want to avoid nicked fingers, keep your hands well out of the way.

When a writer wishes to draw attention to a speech act, he can do so by making it conditional on a proposition that both he and the reader know to be true. While this constuction does not occur with other SCs, it is 
clearly a different PRAGMATIC use of if, which does not require a different meaning of if.

\section{Conditional speech acts}

We turn now to non standard uses in which the protasis proposition is indeed in doubt, but the inference relation is non standard. We showed that Austin's if of doubt or hesitation can be considered as a conditional speech act rather than as a speech act in which there is a conditional. Conditional speech acts are made when the writer does not know whether or not a speech act is appropriate in the circumstances, but he believes that the reader does know. Most (4/6) of our examples are of this form:

(189) If you would feel happier with full collision insurance, there is a small additional charge (...)

(209) "You may come back to Strasbourg, now, if you wish."

The other use in the sample $(2 / 6)$ is when the writer wishes to pose a question but only under the appropriate circumstances:

(190) If you use company transportation to meet trains or haul visitors, would taxis be cheaper?

As has already been pointed out, the speech act can fall within the scope of other SCs. Thus it is not parsimonious to postulate a seperate meaning of if for conditional speech acts.

\section{Performative conditionals}

The scope of the speech act normally includes the inference relation. We have just seen how the speech act may instead occur within this relation. With performative verbs in the apodosis we see a shift the other way; the speech act indicated by a verb in the apodosis is NOT within the scope of the inference relation, despite the fact that the verb occurs in the apodosis. This is the case with Austin's stipulative if, e.g.:

(28) (..) he vowed vengence on Viola Lake if ever the chance came his way.

We have seen that this use also occurs with other SCs, so the use of if within the scope of a performative does NOT require a seperate meaning of if.

\section{Doubtful noun clauses}

We have just looked at two uses of if in which the protasis proposition is indeed in doubt, but in which the inference relation is non standard. We turn now to uses in which the inference relation is absent. The first of these is the use of if to introduce a clause to function as the object of a mental act:

(144) I asked an old guy (...) if the boat was Moore's. $A$ range of verbs involving questions take this construction:

wonder if, when the agent has the question in his mind; see if, when the agent tries directly to answer his question;

ask if, when the agent puts his question to a third party;

know if, when the agent has the answer to a question in the mind of the speaker;

doubt if, when the agent believes that the answer to a question in the mind of the speaker is probably negative. This construction is not found with other SCs, except for whether; nor is there any question of it being subsumed under any of the other uses of if. So it is an apart meaning of if.

\section{Doubtful presuppositions}

A frequent non standard use is to cast doubt on a presupposition of the main clause. Just as with the use of if to introduce a noun clause, the protasis proposition is in doubt - more, it is being put into doubt - and there is no inference relationship from the protasis to the apodosis proposition. The presuppositions that were denied in this way in the sample were:

-existence, presupposed by a noun (4/17):

(77) But it also made him conspicuous to the enemy, if it was the enemy (...)

-an event, presupposed by the use of a verb $(3 / 17)$ :

(159) Perfect, complete entities, if they move at all, do not move towards what they lack.

-number and place, presupposed by certain adjectives or adverbs, which are put into doubt using if any(where) $(5 / 17)$ :

(10) Few areas, if any, (...)

(16) For here, if anywhere, (...)

-and possibility or necessity, presupposed by imperatives and promises or threats (2/17):

(110) Begin the examination of a site with a good map and aerial photos, if possible.

(100) The posse then asked that he send out the women and children as the building would be fired $(. .$.$) if necessary to take him dead or alive.$

There is also the interesting case in which a complex entity which is doubtful enters into a proposition. This is done by placing the complex entity into the protasis, together with ever, and referring to it in the apodosis (3/17):

(149) If there was ever a thought in her mind that (...), it was now dispelled.

It might be thought that this is a special case of a conditional speech act. However it differs from the latter in that the protasis proposition is not thought by the writer to be decidable by the reader. Rather it is in the nature of a hedge against a possible, but not highly probable, state presupposed by the apodosis. Thus we have classified it as having no inference relation from the protasis to the apodosis.

However there is some relationship between the protasis and the apodosis, best characterised as an alternative relationship. The apodosis proposition is doubtful because one aspect, $x$, within it may not be applicable. Thus where $x$ occurs in the apodosis proposition there must be ( $x \vee$ not-p), e.g. 10 could be:

number of areas (small $v$ not-one).

This proposal is related to material implication in standard symbolic logic: $\mathbf{p} \quad \boldsymbol{x}$ is equivalent to not-p $\mathbf{v} \mathbf{x}$.

\section{Restrictives}

In contrast to an if phrase indicating that a word may go too far because a presupposition may not hold, an if 
not phrase is used to indicate that the word being used, a noun or an adverb, may not go far enough:

(102) And social relations arising out of business ties impose courtesy, if not sympathy, toward (...)

(105) (...) the inevitable time crisis experienced by most (if not all) adolescents in our society (...)

Can this use of if not be derived from another use of if, together with not, or is it a different use in its own right? There are three possibilities for the derivation: that the if not phrase is derived from an if not clause, that the restrictive use is found with other SCs with not, and that the restrictive use can be derived from another use of if in a phrase.

Consider the first possibility, i.e. that the restrictive use of an if not phrase is simply an abbreviated form for an entire clause, e.g. 102 would be derived from:

(102') And if social relations arising out of business ties do not impose sympathy, they impose courtesy toward (...)

But if this is the case then 102' should be either a standard conditional use of if or one of the non standard uses. It is certainly not a standard use as the apodosis, at least of the original, is asserted simpliciter. However, neither is it a factual use as the protasis is not asserted, but left open. This suggests that it might be a conditional speech act; but 102' lacks an important feature of conditional speech acts, namely that the speaker expects the listener to know whether the protasis proposition is true or not. So, while the restrictive use of if not to introduce a phrase can be derived from an if not clause, this does not help matters as this use would in itself be different from any other.

The second possibility is that the restrictive use of if not occurs with other SCs. There is only one other SC that has this syntactic construction, namely although. However semantically there is a difference from this concessive use of although, e.g.

Most although not all adolescents in our society (...) is definitely a restriction to 'not all adolescents' rather than a possible restriction to 'all adolescents'. So there is NO similar use for the other SCs that is semantically equivalent to this restrictive use of if not.

We turn now to the last possibility, other if phrases. There are two: the concessive use (see below) and the doubting of a presupposition. To show that the restrictive use cannot be derived from the concessive use consider this ambiguous example:

The establishment offered a longlasting, if not permanent, cure.

This can have a restrictive interpretation, i.e. that the cure is certainly longlasting and may well be permanent. But it can also have a concessive interpretation as can be seen when 'not permanent' is replaced by 'temporary':

The establishment offered a longlasting, if temporary, cure.

So the restrictive use cannot be derived from combining not with the concessive use of if lotherwise there would be no ambiguity).

Rather the restrictive use is semantically equivalent to the use of doubting a presupposition. The relationship in the latter case we have classified as ( $\mathbf{x}$ v not-p), where $x$ is an entity in the apodosis. The restrictive use is identical. For a sentence of the form $q$ if not $p$, the relationship is ( $\mathbf{x} \mathbf{v} \mathbf{p}$ ), where once again $x$ is an entity in the apodosis. For example the relevant phrase in 105 could be formalised as

number of adolescents (large $v$ all).

Compare this with the formalisation for 'few areas if any':

number of areas (small v not-one).

While the equivalence to the if of doubtful presupposition holds at this level, restrictive if has a different function. In the former the protasis introduces a doubt about the legitimacy of something presupposed in the main clause; the latter proposes a possible replacement for something in the main clause.

We conclude that the restrictive use of if not is derivable from the same logical structure as the use of if to doubt a presupposition and so does NOT introduce a new meaning of if.

\section{Concessives}

Another use of if in which the apodosis proposition is true and in which there is no inference relation, is a concessive use. It occurs only with an adjective in the protasis:

(5) (...) now that you have finally grown up, if a little late (...)

(121) (...) a well known establishment for the speedy if temporary rehabilitation of drunkards (...)

This use cannot be reduced to the standard conditional meaning of if by claiming that the phrase in the protasis has been reduced from some complete clause. If we try to do so, as in:

(5') You have finally grown up, if you have grown up a little late.

the result is not a standard conditional but rather a factual, but one which contains new information in the protasis; no such factuals occurred in our sample. So the concessive use of if phrases cannot be derived from a underlying if clause use.

As we have already seen, it is possible that a non standard use of if has a counterpart with other SCs. The only other SC that permits a similar construction is although:

You have finally grown up, although a little late. which is almost a paraphrase of 5 . But it is unlikely that this concessive use of if is a 'mistake' for although; certain authors use concessive if phrases consistently, e.g. Schoenberger (1969). A possible difference between the two is that the adjective following although is definitely applicable, c.f.

A speedy although temporary rehabilitation.

A speedy if temporary rehabilitation.

This suggests that there is a relation between the concessive use and the use to indicate a doubtful presupposition. Here what is put into doubt is not the presupposition but a likely connotation of a word, e.g. rehabilitations are normally permanent. However the logical relation is NOT the same, e.g. it is not the case that 'speedy if temporary rehabilitation' can be formalised by:

time for rehabilitation (short) 


\author{
duration of rehabilitation (permanent $v$ not- \\ temporary); \\ rather it is
}

duration of rehabilitation (permanent $v$ temporary).

So the concessive use of if cannot be reduced to the use to doubt a presupposition. We have also shown that it cannot be derived from a standard or factual if clause; nor do other SCs exhibit the same phenomenon. So the concessive use of if must be considered as being based on a different meaning of if.

\section{Protasis only}

One of the uses of if that, within our sample, occurs only within reported speech, is when the speaker puts forward a possibility which in itself is sufficient to cause a reaction in the listener:

(187) "If you want to see" ... "Never mind", she said sternly.

(200) "But if you say you managed it ---" The stanger was hooked.

It is the pragmatics of the context that leads to the protasis being sufficient to cause the speaker to stop or the listener to interrupt, so no new meaning of if is required.

\section{Summary}

The non standard examples of if sentences have been divided into 9 sub-categories within the three categories that we proposed above. Is there any post hoc rationale that can be given for these categories? Are they necessary or complete?

Within category $\mathrm{A}$, in which the protasis proposition DOES have a truth value, there are two subcategories, counterfactuals and factuals, which correspond to the protasis proposition being false and true respectively. However this is not the only difference between the two: counterfactuals have a standard inference relation from the protasis to the apodosis proposition, while factuals do not. For the factuals it is the speech act that is conditional upon the protasis proposition.

Why is it that we do not find two other subcategories: false protasis with conditional speech act and true protasis with standard inference? There is no pragmatic situation in which the former might occur; if both the writer and the reader know that the protasis proposition is false, then the speech act would never be accepted at all. For the latter there is another SC which fulfills the function, namely non-temporal since.

Neither do we find the condition falling within the scope of a performative verb in category A. It cannot occur with counterfactuals as the performative would have to be countered in which case it would no longer be performed, e.g.

I would have promised to marry him if he had asked me.

is simply no promise at all but a standard counterfactual. Neither have we been able to construct a factual within a performative. So there are no sub-categories missing from $A$.
Within the Bl category, with non standard inference, we find a symmetrical situation. For the conditional speech act, the speech act is moved IN to within the scope of the protasis; for the performative use the main verb in the apodosis is moved OUT beyond the scope of the protasis. Thus we do not expect to find further subcategories within Bl.

Within the B2 category, in which the inference relation is absent, we found 5 sub-categories within the sample. In the sub-category in which if introduces a noun clause there is no apodosis; if is being used just to introduce a proposition with unknown truth value. There is another sub-category with no apodosis, when the protasis is sufficient for the speaker to stop.

The remaining 3 sub-categories within $B 2$ are all related in several ways: the protasis may be a phrase (in two cases, restricitive and concessive use, it MUST be a phrase); while the protasis is in doubt the apodosis proposition is true, with a minor exception; this exception is being put forward in the protasis as possibly although not necessarily the case. In the restrictive use (if not) the writer suggests the possibility of a further restriction to one of the features of the apodosis; in the use to doubt a presupposition, the apodosis, on the contrary, goes too far in one of its presuppostions; in the concessive use it is not something as strong as a presupposition that goes too far but just a likely connotation of a phrase within the apodosis. While there is some pattern to this B2 category, we believe that it is essentially open; innovative uses of if will be found here rather than in the other two categories.

\section{CONCLUSION}

We have found 9 different non standard uses of if, as summarised in Table 1. However this does not require there to be 9 different meanings for if. Three meanings are sufficient.

Four of the different uses are explainable by pragmatic considerations, a point we made when criticising Austin's claim. His two ifs are the two uses in category $\mathrm{Bl}$; the differences arise from differences in the scopes of the speech act and the conditional and are common to other SCs. The factual use occurs when both the writer and reader know that the protasis proposition is true and is used for emphasis. Lastly the protasis may occur without an apodosis when the speaker is interrupted. All four uses are based on the standard conditional meaning of if; the non standard uses arises from pragmatic considerations.

The counterfactual use arises from an interaction with the subjunctive mode in the apodosis. This is common to other $\mathrm{SC}$ s and so does not require an apart meaning of if.

The use of if to introduce a noun clause DOES require an apart meaning of if as no inference relation is present. This suggests that the feature of if to introduce a proposition of unknown truth value is predominant over the inference relationship feature. The factual use of if is the only use in which the former feature is absent; then it is a stylistic consideration that leads to the use of if, i.e. 
to add emphasis.

The three remaining uses are possible candidates for a third meaning of if, as none display an inference relationship. These uses cannot be accounted for by some pragmatic variation of the standard conditional, such as a shift in the scope of the speech act, nor are similar uses found with other SCs in general. In two of these uses, restrictive and concessive, the protasis must be a phrase; but these phrases cannot be derived from a corresponding standard conditional clause.

Two uses, doubtful presuppostion and restrictive, have a semantic feature in common, namely that there is some feature of the apodosis, $x$, which may need to be modified. We propose that if here has a meaning equivalent to material implication, i.e. $x$ v not-p, which is equivalent to $p \supset x$. This is the traditional logicians suggestion for the standard meaning of if.

We do not accept that in the standard conditional use the meaning of if is equivalent to material implication; such an equivalence runs into difficulties. For instance it requires the equivalence of:

If I hit you, it'll hurt.

Either I don't hit you or you'll be hurt. and such unacceptable reasoning as:

God doesn't exist, so if God exists we are free to do what we want.

Several attempts to save the equivalence have been made. For instance Grice (1967) did so by requiring that speakers adhere to certain conversational implicatures, such as saying as much as they know, thus ruling out the use of a conditional if sentences with a false protasis. Formal semanticists propose some slight modifications. For instance Stalnaker (1975) claimed that in any context in which a sentence of the form not-p or $q$ is acceptable, a sentence of the form if $p$ then $q$ is also acceptable. Elsewhere (Bree, 1981) we have taken issue with these and other attempts to demonstrate equivalence of if with material implication.

However in the use of if to doubt a presupposition or to make a restriction, the meaning of if can be considered to be equivalent to material implication. It also occurs infrequently (3\%) with standard conditionals:

(62) (...) if I don't put my two cents in, someone else will.

in which there is no inferential relation. This meaning differs from our standard meaning in that the truth of the apodosis proposition is sufficient to confirm the sentence, e.g. knowing that 'someone else will' is sufficient to confirm 62. Similarly for two other uses: with the doubtful presupposition use of if, knowing that the apodosis is true is sufficient to confirm the sentence, as the presupposition is no longer in doubt; with the restricitve use, the apodosis is the minimal assertion that is being made so its truth is sufficient for the truth of the sentence. So the $x \mathbf{v}$ not-p, or material implication, meaning of if accounts for these two uses of if.

The last non standard use of if, the concessive, is an anomaly. There is no question of inference, but neither is there any affinity with material implication, e.g.

speedy if temporary $\neq$ speedy or not temporary. It is possible that this use is a contraction from even if.
We refrain from suggesting a fourth meaning of if. We would expect that translations into other languages would not be to the conditional, e.g. with Dutch if in such expressions is translated using zij het, literally be it.

In conclusion, we propose that if has three different meanings, all of which have one feature in common: the truth status of the protasis is in doubt. They are, in order of frequency of occurence in our sample:

1. inferential $(p \rightarrow q)$ : as used in standard, counterfactual and factual conditionals, together with the conditional speech act, the performative conditional and the use of the protasis without an apodosis (in this last case the inference is left open);

2. material implication ( $q \mathbf{v}$ not-p): as used in a few standard conditionals, for doubting a presupposition and in the restrictive use;

3. doubting: as used in noun clauses, in which only the truth of the associated proposition is put into doubt.

We expect that other languages will use different words for these three meanings. This is the case in Dutch, for example, where the uses depending on an inferential meaning are indicated by als or the more formal indien, the material implication by zo and doubting by of (which is also used to translate whether). There is only one exception to this, the factual use in Dutch is not indicated by als but by a change in word order.

Any computer program which purports to understand the English language will need to be able to distinguish between these three different meanings. The last, doubting, is easy to detect as if is then used to introduce a noun clause as opposed to a sub clause. However distinguishing between the inferential and material implication is not solvable on syntactic grounds. One suggestion is to assume that if has an inferential meaning; if no inference relation can be found, then it must be equivalent to material implication. This should be easy to decide when if is being used to put a presupposition into doubt or in its restrictive use; more difficult would be to detect material implication in standard uses of if.

\section{ACKNOWLEDGEMENTS}

The research reported here was carried out as part of the project "The Semantics of subordinating conjunctions: an information processing approach", supported by the Nederlandse Stichting voor Psychonomie, with funds made available from the ZWO. Project Nr. 15-30-10.

Don Sherman of Stanford University Computing Center kindly provided us with the data for this study.

\section{REFERENCES}

Austin, J.L., Ifs and cans, in J.O.Urmson \& G.J.Warnock, eds., Philosophical papers of J.L.Austin. London; Oxford University Press, 1961.

Bree, D.S., The interpretation of implication, in A.Elithorn \& D. Jones, eds., Artificial and human thinking. Amsterdam; Elsevier, 1973, 273-282. 
Bree, D.S., Can IF be formally represented? Proceedings of the $3 \mathrm{rd}$ annual conference of the Cognitive Science Society. Berkely, 1981, 173-176.

Bree, D.S., Counterfactuals and causality. Journal of Semantics, 1982, 1, 147-185.

Grice, H.P., William James Lectures, Harvard University, 1967. Published in part as "Logic and conversation", in P.Cole \& J.L.Morgan, eds., Syntax and semantics, vol. 3. New York; Seminar Press, 1975, 41-58.

Harper, W.L., Stalnaker, R. \& Pearce, G., Ifs. Dordrecht; Reidel, 1981.

Kucera, H. \& Francis, W.N., Computational analysis of present-day American English. Providence; Brown University Press, 1967.

Rutherford, W.E., Some observations concerning subordinate clauses in English. Language, 1970, 46, 97115.

Schoenberger, W.S., Decision of destiny. Athens, Ohio; Ohio University Press, 1969.

Stalnaker, R.C., Indicative conditionals. Philosophica, $1975,5,269-286$.

Wason, P.C. \& Johnson-Laird, P.N., Psychology of reasoning. London; Batsford, 1972. 